\title{
Research on MPPT Control of Photovoltaic Cells Based on Fuzzy Control
}

\author{
Fengshan Liu ${ }^{1}$, Yanping Wang ${ }^{2 *}$ \\ \{824162388@qq.com¹,wangyp@dlpu.edu.cn² $\}$ \\ Dalian Polytechnic University ,Liaoning province ${ }^{1}$, Dalian Polytechnic University, Dalian Key \\ Laboratory of Smart Micro-grid and Green Recycling Industry, Liaoning province ${ }^{2}$
}

\begin{abstract}
Changes in factors such as light intensity and temperature can cause fluctuations in the power of photovoltaic cells. To solve this problem, this paper proposes a maximum power point tracking strategy (MPPT) based on fuzzy control. According to the fuzzy control algorithm, this paper determines the membership function and fuzzy rules, builds a fuzzy controller, sets up a photovoltaic system, and performs simulation verification in MATLAB/Simulink. The results show that, in terms of tracking speed, compared with the commonly used Perturbation and Observation method, the fuzzy control is improved by five times faster, and the method also has better smoothness and anti-interference.
\end{abstract}

Keywords: Photovoltaic cells; MPPT; Fuzzy logic control; Perturbation and Observation.

\section{Introduction}

Due to the development of society and technology, people's demand for electricity is increasing, coupled with the excessive consumption of traditional fossil energy and the aggravation of environmental problems, people are focusing on clean energy, such as wind, solar, tidal energy, etc.[1]. In recent years, with the development of technology, the proportion of clean energy power generation has increased, and the proportion of photovoltaic power generation has reached $3.1 \%$ at the end of 2019 .

In photovoltaic power generation systems, the output characteristics of photovoltaic cells are not only related to their own materials, but also to environmental factors such as temperature and light intensity. Therefore, making the system run stably at the MPP is a key issue. The current MPPT algorithms include Open Circuit Voltage method, Short Circuit Current method, Perturbation and Observation method, Increment Conductance method, neural network control method, fuzzy control and other intelligent algorithms [2-5].

At present, Perturbation and Observation method is widely used because of its tracking speed is good and the simple structure, while the control accuracy is not high enough in some situations and the tracking speed is not fast enough either.

The better improvement is the variable step size disturbance observation which has high convergence stability [6].This algorithm is generated based on the mathematical principle that the derivative of the MPP power point is 0 . Although the performance of the algorithm is optimized, the calculation of the maximum step size and speed factor is difficult, and sudden

${ }^{*}$ Corresponding author: Yanping Wang

Fund Project: Dalian Science and Technology Innovation Fund(2020JJ26GX029) 
changes in the environment produce dead zone convergence. Literature $[7,8]$ proposed an optimization algorithm for the variable step size perturbation and observation method, but it is unavoidable that the model is too complex and affects real-time response.

However, currently, most MPPT strategy use the same method to track the point. It is to control the DC/DC convert circuit by changing the duty cycle, the output power can stable at MPP $[9,10]$. The fuzzy control method has high control accuracy and fast tracking speed, but the complex structure of the algorithm is also complicated [11].Recently, fuzzy control has become a popular research in the control engineering. The fuzzy logic controller has made itself available not only in the laboratory work but also in industrial applications, such as the cement kiln control and the servo hydraulic cylinder position control [12]. The controller can be regarded as a set of heuristic decision rules derived from the experienced operator.

The main advantages of fuzzy control are no mathematical formulation of the system is needed and linguistic variables and approximate reasoning are used to describe the inexact objects and achieve multi-objective control [13].The main work this paper done is design a fuzzy logic controller to adjust the duty cycle so as to control the power electronics. The core of a fuzzy logic controller is to establish fuzzy tables and fuzzy rules [14, 15]. Fuzzy rules are usually summed up by expert experience, engineering experience and practice [16]. This paper improves the membership function and the fuzzy rules based on the traditional fuzzy control method.

The overall methodology for planned research is organized as follows: Section 2 introduces the construction of photovoltaic cells and the system, Section 3 introduces the fuzzy control method, Section 4 introduces the disturbance tracking method, and the final section compares and draw conclusion.

\section{Photovoltaic cells and the system}

\subsection{Photovoltaic cells}

Photovoltaic power generation is a power generation system that uses the photoelectric effect to convert solar energy into electrical energy. It has the advantages of high reliability, cleanliness, and grid connection, and is favored by all over the world. The structure of the photovoltaic cell is similar to the PN junction. When there is light, it will generate voltage. According to its principle, the equivalent circuit of the photovoltaic cell can be obtained, as shown in Figure 1.

According to the paper $[17,18]$ and the equivalent circuit diagram, the I-V equation can be obtained :

$$
\begin{aligned}
I & =I_{S C}\left[1-C_{1}\left(\exp ^{V / C_{2} V_{o c}}-1\right)\right] \\
C_{1} & =\left(1-\frac{I_{\mathrm{m}}}{I_{S C}}\right) \exp ^{-\mathrm{V}_{\mathrm{m}} / \mathrm{C}_{2} \mathrm{~V}_{\mathrm{oc}}} \\
C_{2} & =\left(\frac{V_{\mathrm{m}}}{V_{\mathrm{oc}}}-1\right)\left[\ln \left(1-\frac{I_{m}}{I_{s c}}\right)\right]^{-1}
\end{aligned}
$$




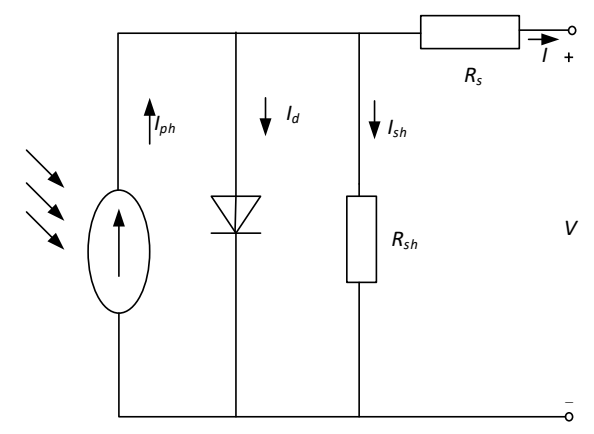

Fig. 1. Photovoltaic cell equivalent circuit diagram

The above is an engineering model, which will be affected in the actual environment, so it needs to be corrected.

$$
\begin{aligned}
& V_{o c}^{\prime}=V_{o c}(1-c \Delta T)(1+b \Delta S) \\
& V_{m}^{\prime}=V_{m}(1-c \Delta T)(1+b \Delta S) \\
& I_{S C}^{\prime}=\frac{I_{\mathrm{sc}} S}{S_{0}}(1+\alpha \Delta T) \\
& I_{m}^{\prime}=\frac{I_{m} S}{S_{0}}(1+\alpha \Delta T)
\end{aligned}
$$

Standard battery temperature: $T_{0}=25^{\circ} \mathrm{C}$; standard light intensity: $S_{0}=1000 \mathrm{~W} / \mathrm{m}^{2}$; constant $a=0.0025 /{ }^{\circ} \mathrm{C}, b=0.5, C=0.00288 /{ }^{\circ} \mathrm{C}$, the parameters of the photovoltaic cell selected in this article are: $V_{o c}=38.3 \mathrm{~V}, V_{m}=31.2 \mathrm{~V}, I_{o c}=9.29 \mathrm{~A}, I_{m}=8.70 \mathrm{~A}, P=270 \mathrm{~W}$. Based on the formula and these parameters, the photovoltaic cell is modeled shown in Figure 2. And the simulated P-U curve under different light intensity and the same temperature is shown in Figure 3.

\subsection{Photovoltaic system}

In the smart micro-grid, distributed power generation is the core, and there are many distributed power sources. Nowadays, photovoltaic systems are widely used. In addition to the structure of the photovoltaic cell, the external environment has a great influence on it. The main influencing factors are light intensity and temperature. Under different external conditions, there will be different characteristic curves, and in each case there will be a maximum power point. The power point is very important to ensure that the system runs at the maximum power point as much as possible [19]. The photovoltaic system studied in this paper is mainly based on changing the duty cycle of the power electronic devices of the DC/DC converter. The simulation model of integrated MPPT control is mainly composed of photovoltaic cell modules, DC/DC convert circuit, MPPT control module and PWM module, and the voltage and current detection circuit. When the output voltage and current of the photovoltaic cell are measured, they are sent to the MPPT module. The MPPT controller performs optimal output and serves as the input of the PWM module to make the PWM adjust the duty cycle of the switching device of the DC/DC circuit to stabilize the photovoltaic cell at the maximum power output state.

The composition of the photovoltaic system is shown in Figure 4. And the simulation in SIMULINK of the system is shown in Figure 5. 


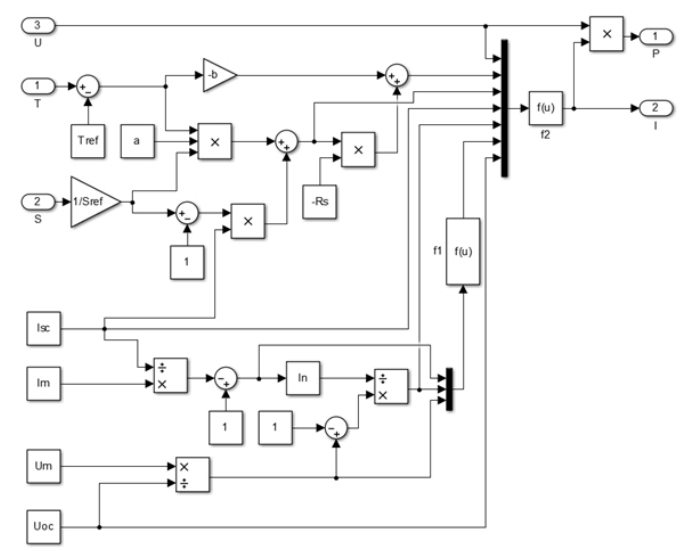

Fig. 2. Photovoltaic cell model

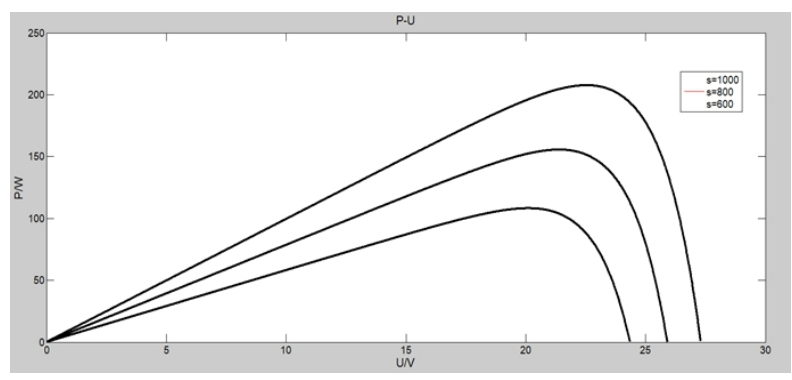

Fig. 3. P-U curve under different light intensity

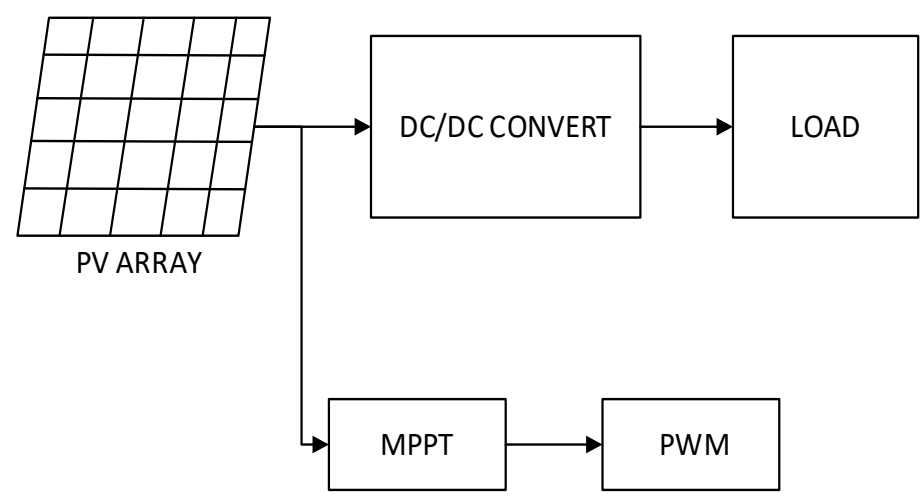

Fig. 4. The composition of the photovoltaic system 


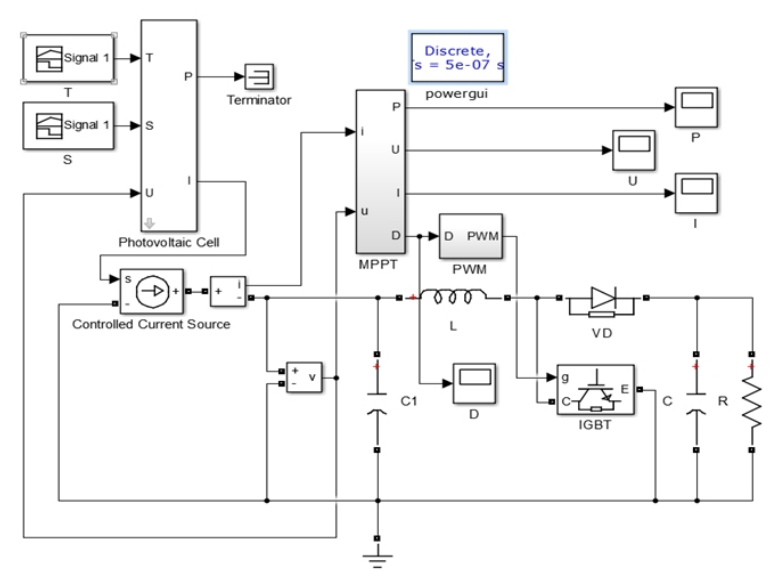

Fig. 5. The simulation of the photovoltaic system

\section{Perturbation and Observation}

The principle of the perturbation and observation method is to perturb the voltage, and then control the system according to the change of the power before and after the disturbance point [20].If power increases, the disturbance continues in the same direction; if the power decreases, the disturbance is applied in the opposite direction. Figure 6 shows the model of the P\&O control method with fixed step in MATLAB/Simulink.

The perturbation and observation method used to increase or decrease the voltage at a fixed step length, and constantly compare the power after the voltage change. However, due to the inherent contradiction between the response speed and stability caused by the setting of the step size, the variable step size perturbation and observation method like Figure 7 was developed later to collect the current and voltage values, calculate the power difference between the power value and the sampling points before and after, set the disturbance coefficient, In the early stage, use a large step size to approach quickly, change

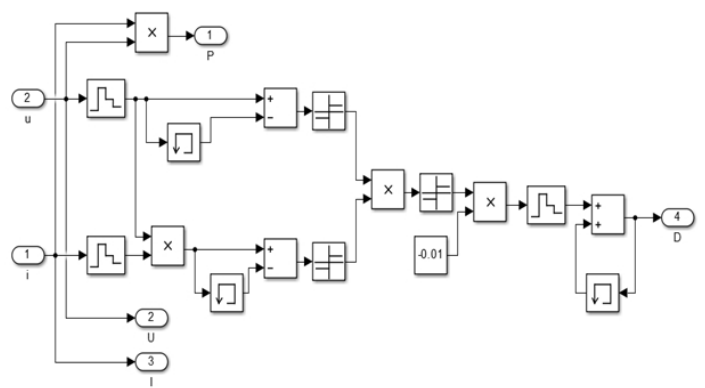

Fig. 6. The model of the $P \& O$ with fixed step 


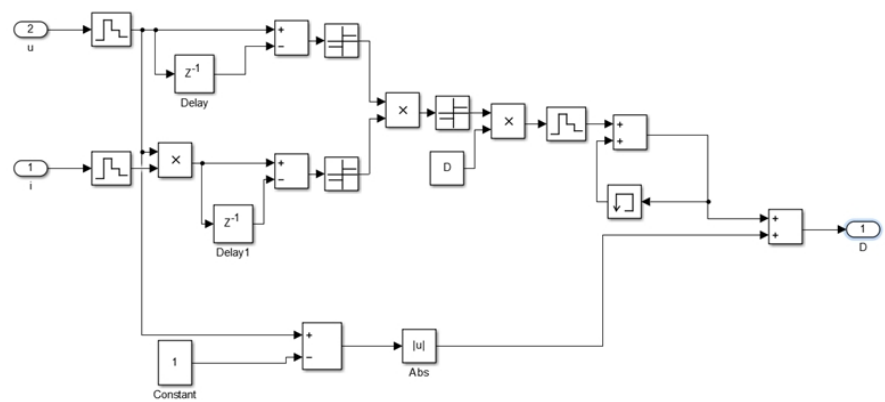

Fig. 7. The model of the $\mathrm{P} \& \mathrm{O}$ with variable step

the step size in the later stage, use a small step size, and then use iteration to make the step size smaller and smaller, which can quickly stabilize the MPP and minimize the amplitude.

\section{Fuzzy Logic Control}

Human thinking mainly relies on conceptual patterns and thinking images, rather than quantity, but the basis of computer work is just the opposite. Natural language, which is the shell of human thought, naturally has a silent house type, which computers cannot understand. Fuzzy control is based on the combination of fuzzy theory and fuzzy logic reasoning. It converts the knowledge and control experience expressed in expert language into mathematical functions through fuzzy theory and then uses computers for processing.

As the complexity, non-linearity, hysteresis and coupling of control objects increase, people's ability to acquire accurate knowledge is relatively reduced, and the possibility of using traditional precise control is also reduced, and fuzzy control has emerged. Fuzzy logic control (FLC) is a kind of language logic controller, which includes: Data acquisition- Fuzzification Fuzzy rule logic reasoning- Defuzzification-output and other processes [21] shown in Figure 8.

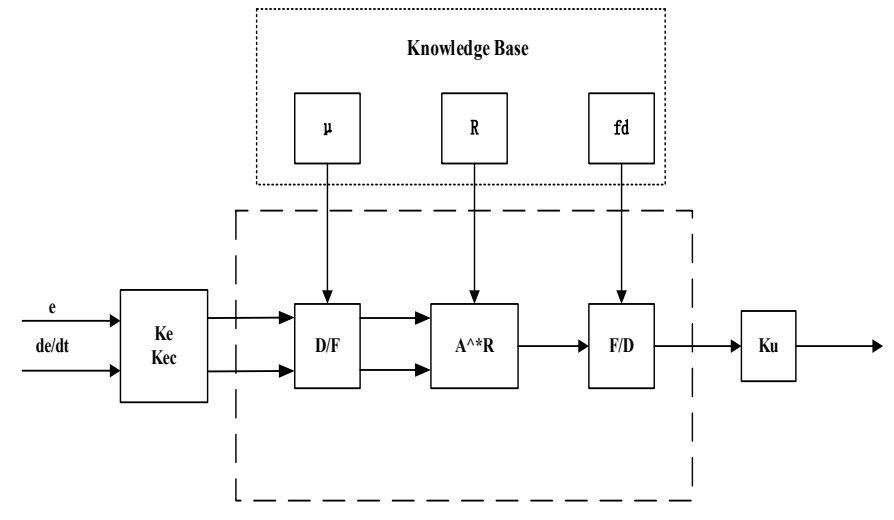

Fig. 8. Fuzzy controller schematic diagram 
In physical systems, it is sometimes difficult to describe a complex system using the linearization or identification techniques. Takagi and Sugeno used fuzzy implications to express a complex system which is called the fuzzy model. In general, the construction of the fuzzy model is based on physical properties of the system, the input-output data, and the corresponding empirical knowledge and so on.

When designing the fuzzy controller, $\mathrm{d} P / \mathrm{d} V, \Delta \mathrm{d} P / \Delta \mathrm{d} V$ is obtained as the deviation $E$ and the deviation change rate $E C$ through continuous sampling of the output voltage and current of the photovoltaic cell:

$$
\begin{gathered}
e(k)=\frac{P(k)-P(k-1)}{U(k)-U(k-1)} \\
e_{c}(k)=e(k)-e(k-1)
\end{gathered}
$$

After quantizing factors $K e$ and $K e c$, the input variables are mapped to the fuzzy controller, and the output is obtained. Define 7 fuzzy subsets respectively to represent negative large, negative medium, negative small, zero equal, positive small, positive middle, and positive large. Their membership function is shown in the Figure 9 and Figure 10.

$$
\left\{\begin{array}{l}
e=\{N B, N M, N S, Z E, P S, P M, P B\} \\
e_{c}=\{N B, N M, N S, Z E, P S, P M, P B\} \\
u=\{N B, N M, N S, Z E, P S, P M, P B\}
\end{array}\right.
$$

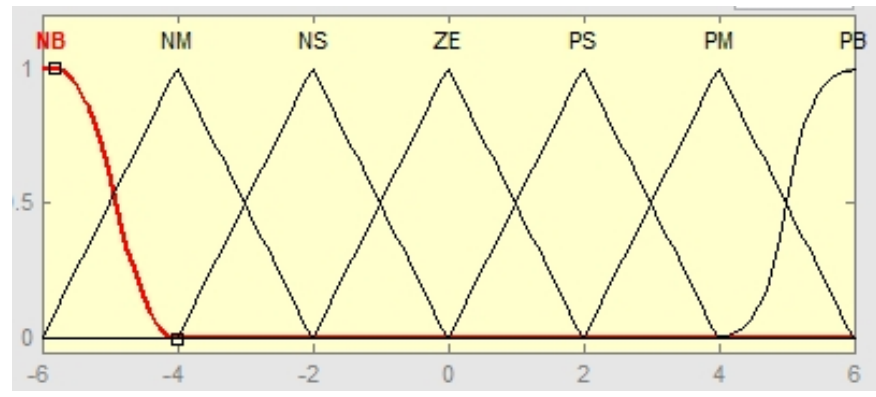

Fig. 9. The membership function of $\mathrm{d} P / \mathrm{d} V, \Delta \mathrm{d} P / \Delta \mathrm{d} V$

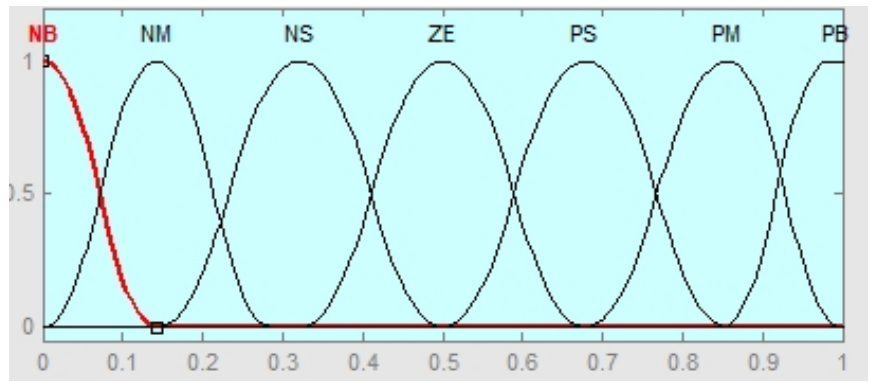

Fig. 10. The membership function of $D$ 
Table 1. Fuzzy rules

\begin{tabular}{|c|c|c|c|c|c|c|c|}
\hline $\mathrm{EC}$ & NB & $\mathrm{NM}$ & NS & $\mathrm{ZE}$ & PS & $\mathrm{PM}$ & PB \\
\hline NB & $\mathrm{PM}$ & PB & $\mathrm{PM}$ & NB & $\mathrm{NM}$ & $\mathrm{NB}$ & $\mathrm{NM}$ \\
\hline NM & $\mathrm{PM}$ & $\mathrm{PM}$ & PS & NM & NS & $\mathrm{NM}$ & $\mathrm{NM}$ \\
\hline NS & PS & PS & PS & NS & NS & NS & NS \\
\hline ZE & $\mathrm{ZE}$ & ZE & ZE & ZE & ZE & ZE & ZE \\
\hline PS & NS & NS & NS & PS & PS & PS & PS \\
\hline PM & $\mathrm{NM}$ & $\mathrm{NM}$ & NS & $\mathrm{PM}$ & PS & PS & PM \\
\hline PB & $\mathrm{NM}$ & NB & NM & PB & $\mathrm{PM}$ & PB & PM \\
\hline
\end{tabular}

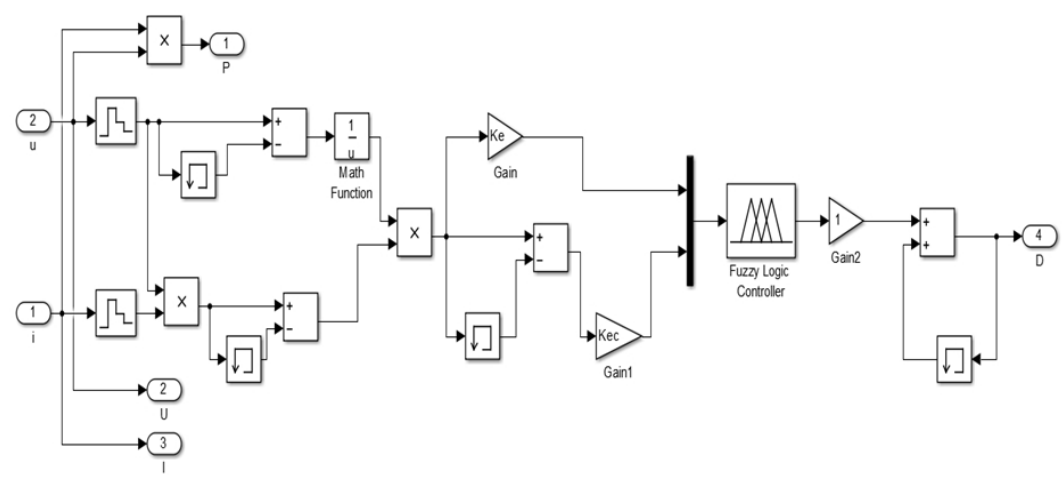

Fig. 11 The model of MPPT with fuzzy controller

The core of the fuzzy controller is the fuzzy control rules. This article establishes a fuzzy rule table as shown in the Table 1. These rules are based on when the change of $E$ and $E C$ causes the output power to change, according to the fuzzy rule table, the output power returns to the MPP. The establishment of the fuzzy control table is mainly based on experience, theoretical analysis, and expert experience, among which expert experience is the leading source.

In this paper, the Mamdani model is selected as the fuzzy controller model, the input membership function chooses the triangle, and the output membership function chooses the Gaussian type, because the triangle and the Gaussian membership function have good adaptability, and the operation is convenient and the performance is familiar. The input variable selects the triangular membership function, and the output selects the Gaussian membership function because of the convenience of calculation, which can improve the resolution, so that the accuracy becomes higher and the error is reduced. The method clear to fuzzy conversion chooses the larger and the smaller synthesis method, because the calculation is small and the calculation speed is fast, the area-gravity method is used for the method of blur to clear conversion, because although the calculation is larger, it is intuitive and reasonable, and it is well-founded, more accurate. 


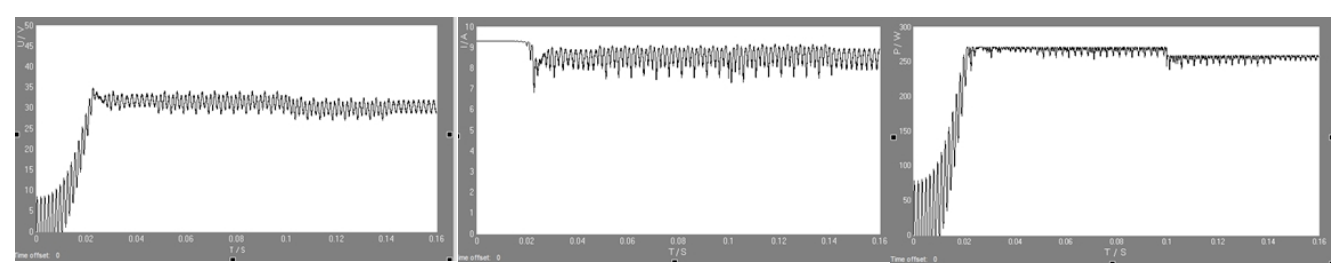

Fig. 12. The simulation of $\mathrm{P} \& \mathrm{O}$

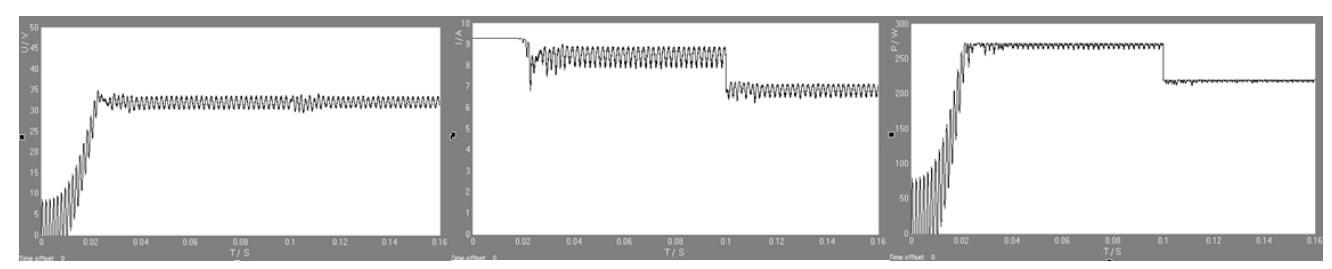

Fig. 13. The simulation of FLC

Build a model base on these parameters and math formula shown in Figure 11.

In order to compare the optimization ability of the fuzzy control method for the system, the simulation model is used for simulation. Set the same simulation time to $0.16 \mathrm{~s}$, keep the temperature constant at 25 , and the initial light intensity to 1000 , which will decrease to 800 at $0.1 \mathrm{~s}$ for simulation. The Figure 12 shows the simulation of voltage, current and power of $\mathrm{P} \& \mathrm{O}$ and Figure 13 shows the simulation of voltage, current and power of FLC (Fuzzy logic control).

The simulation results are shown in the figure. Two methods to track to the maximum power point. The voltage fluctuation of the perturbation and observation tracking method is 5 volts, the current fluctuation is $1.8 \mathrm{~A}$, and it takes 0.022 seconds to regain the stable state; the Fuzzy logic control tracking method, the voltage fluctuation is 3 volts, the current fluctuation is $1 \mathrm{~A}$, and it takes 0.005 seconds to regain the stable state.

\section{Conclusion}

This article uses the same photovoltaic model and only changes the control strategy for simulation. It can be seen from the simulation results that both methods can finally reach the maximum power point, indicating that the two algorithms meet the functional requirements, but the performance is quite different. The results show that the output current, voltage and power using the perturbation and observation method will fluctuate after being stabilized, and it will be slow to reach a stable state. This is caused by its own structure, but the output current, voltage and power obtained by the fuzzy control method although there are fluctuations, the fluctuations are relatively small, that is, the so-called smoothness is good, and the speed to reach the optimal solution is also shorter, which shows that the tacking speed is good. When encountering a sudden situation, in this article, which is, when the external conditions suddenly change, it takes longer for the perturbation and observation tracking method to reach a stable state again than using the fuzzy logic control method, so the anti-interference ability of the fuzzy control method is much stronger.

It can be concluded that fuzzy control is more suitable for nonlinear time-varying systems. Considering the actual project, the external conditions of the photovoltaic system are changing 
all the time, so the fuzzy control method is more suitable for actual projects. Although the fuzzy logic control system has the above advantages, the design of a fuzzy controller is based on trialand-observation procedures and there is still no analytical tool to analyze the stability of the fuzzy control system. And the actual cost of the fuzzy control method is relatively higher, which is a problem that needs to be solved in the future. These factors hinder the engineering application of fuzzy control.

\section{Acknowledgments}

Authors acknowledge the financial support of Dalian Science and Technology Innovation Fund (Grant: 2020JJ26GX029) and would like to express many thanks the support of Dalian Key Laboratory of Smart Micro-grid and Green Recycling Industry.

\section{References}

[1] Ahmed J., Salam Z.: An accurate method for MPPT to detect the partial shading occurrence in a PV system. IEEE Trans And Inform. Vol. 13. pp. 2151-2161 (2017)

[2] Patel, A (Patel, Amit)., Tiwari, H (Tiwari, Harpal).: Implementation of INC-PI MPPT and Its comparison with INC MPPT by Direct Duty Cycle Control for Solar Photovoltaic Employing Zeta Converter. International Conference on Information, Communication, Instrumentation and Control. pp. $1-6(2017)$

[3] Jain, K (Jain, Kriti)., Gupta., M (Gupta, Manju)., Bohre., AK (Bohre, Aashish Kumar).: Implementation and Comparative Analysis of $\mathrm{P} \& \mathrm{O}$ and INC MPPT Method for PV System. India International Conference on Power Electronics. pp. 1-6(2018)

[4] A Rajavel., N Rathina Prabha.: Fuzzy logic controller-based boost and buck-boost converter for maximum power point tracking in solar system. Transactions of the Institute of Measurement and Control. pp. 1-13(2020)

[5] Farayola., AM (Farayola, Adedayo M.).,Sun, YX (Sun, Yanxia) ., Ali A (Ali, Ahmed).: ANN-PSO Optimization of PV Systems Under Different Weather Conditions. International Conference on Renewable Energy Research and Applications. pp. 1363-1368 (2018)

[6] Fengcong Lan., Wenjie Li., Zhijie Li.: Deformation response of squeeze load and internal short circuit failure analysis of vehicle power battery, Journal of South China University of Technology. Vol. 46. pp. 65-72(2018)

[7] Huifeng Li., Jing Pang., Shigang Lu.: Research on the safety of lithium-ion batteries under abuse conditions. Power technology. Vol. 37(12). pp. 2235-2238(2013)

[8] He Li., Shenju Yu., Zhikui Chen.: Reactor for internal short-circuit failure of lithium ion battery Scientific research. Electrochemistry. Vol. 16(2). pp. 185-192(2010)

[9] Bruno W França., Mauricio Aredes., MAYNARA Aredes.: Fuzzy adaptive P\&O control for MPPT of a photovoltaic module. Journal of power \& energy engineering. Vol. 2 (4). 120-129(2014)

[10] Huan-Liang., T.: Insolation-oriented model of photovoltaic module using MATLAB/Simulink. Solar Energy. Vol. 84(7). pp. 1318-1326(2010)

[11] Walker., G.: Evaluating MPPT converter topologies using a MATLAB PV model. Journal of Electrical \& Electronics Engineering, Australia. Vol. 1(1). pp. 49-56(2001)

[12] Umbers and P. King.: Analysis of human decision-making in cement kiln control and the implication for automation. Internet Man-Machine Studies. Vol. 12. pp. 9-64(1976)

[13] P.C. Chen and M.C. Shih.: An experimental study on the position control of a hydraulic cylinder using a fuzzy logic controller. JSME Series. Vol. 34(4). pp. 481-489(1991)

[14] Patel R., Panda AK.: Real time implementation of PI and fuzzy logic controller based 3-phase 4wire interleaved buck active power filter for mitigation of harmonics with id-iq control strategy. International Journal of Electrical Power \& Energy Systems. Vol. 59. pp. 66-78(2014)

[15] F.Bouchafal., D.Beriberl, M.S.Boucherit.: Modeling and simulation of a gird connected PV generation system With MPPT fuzzy logic control. International Multi-conference on 
Systems, Signals \& Devices. pp. 1-7(2010)

[16] Dorin Petreus., Toma Pa tara u., ete.: A novel maximum power point tracker based on analog and digital control loops. Solar Energy. pp. 588-600(2010)

[17] Piegari L., Rizzo R.: Adaptive perturb and observe algorithm for photovoltaic maximum power point tracking. Renewable Power Generation. Vol. 4(4). pp. 317-328(2014)

[18] Zhao Y., Zhao X., Zhang Y.: MPPT for photovoltaic system using multi-objective improved particle swarm optimization algorithm. TELKOMNIKA Indonesia Journal of Electric Engineering. Vol 12(1). pp. 261-268(2014)

[19] Yang P., He T., Xu Z R., et al.: A novel region partition MPPT method based on variable stepsize INC. IEEE Innovative Smart Grid Technologies - Asia. Melbourne. IEEE. pp. 299-704(2016)

[20] Patcharaprakiti N., Premrudeepreechacharn S., Sriuthaisiriwong Y.: Maximum power point tracking using adaptive fuzzy logic control for grid-connected photovoltaic system. Renewable Energy. Vol. 30(11). pp. 1771-1788(2015)

[21] Ze Cheng., Hongzhi Yang., Yanli Liu.: Self-adjusting Fuzzy MPPT PV System Control by FPGA Design. IEEE. pp. 1-4(2015) 